\title{
IS A JOURNAL OF METHOD STILL NECESSARY?
}

\author{
JAN VANSINA \\ UNIVERSTTY OF WISCONSIN-MADISON
}

Thirty-four years ago David Henige launched History in Africa (hereafter $H A$ ) at a time when scholars often cut corners in their rush to construct a history of Africa, and disregarded rules of evidence, thereby running the risk that many of their reconstructions would prove to be unsound. The question was not that these scholars were wholly indifferent to methodology, but that the precolonial history of the continent was the cynosure of the field at the time, and hence that all eyes were turned towards the use of oral sources to overcome the perceived scarcity of written sources for that period and to provide voices from the continent. In their haste to fill huge voids in the story of Africa's past, scholars debated the rules of evidence in relation to such unconventional sources. They often disregarded almost every methodological canon when it came to written data. Crucial differences between primary and secondary sources were ignored, archival research was scanty, new editions of older publications were mere reprints accompanied or not by new introductions that were so uninformed as to be useless, while issues about authenticity, authorship, chronology, or translation were all brushed aside as quibbles. Thus, in the days before 1974, methodological concerns focused exclusively on oral tradition and oral history to the detriment of everything else. As its initial editorial made clear, $H A$ was launched as a forum where scholars interested in method could publish articles about all the facets of the historical method-from epistemology to heuristics, rules of evidence, and historiography. The journal was founded and the contributors came.

Today, a long generation later, $H A$ has become a leading journal in the field and seems to have fulfilled most of its mission. First and foremost it has dwelled on every methodological facet concerning work with written 
sources, from finding them to reading them, combining them, editing them, translating them, evaluating them, and interpreting them. ${ }^{1}$ It has also published a great deal about methods for handling oral traditions and the plethora of particular problems they raise, from the initial fieldwork to their final interpretation, and the necessity to make them available by making them accessible in a public repository. Besides narrative sources, contributors have also discussed iconographic and cartographic studies and have probed most sorts of particular historical arguments from extrapolation to the argument of silence. There also has been a lively interest in historiography.

On the other hand, the journal has not developed all the themes and topics the editor called for in his inaugural preface. It contains, for instance, rather little about the many issues concerning oral history proper, that is testimony from eyewitnesses or contemporary hearsay, and not much more about particular questions relating to quantitative data, on the use of fiction as a source for history, and on interdisciplinary research. Although $H A$ has carried a few memorable articles on structuralism and Marxism, the journal has attracted few contributions dealing with the epistemology, philosophy, and the general theory of history. Most authors with such concerns seem to have preferred to write for general journals rather than for this Africanist one. As a consequence $H A$ has carried little or nothing pro and con about such topics and practices as the validity of critical theory and postmodernism or about issues of memory and history.

Meanwhile, most historians of Africa have shifted their sights from precolonial or nineteenth-century history to colonial and postcolonial times in the twentieth century, with the consequence that the mix of sources they use is vastly different from the ones available for the study of earlier periods that are so well represented in the pages of $H A$. Given the plethora of written sources for more recent times, some are wondering whether they should worry at all about method when they think that all they have to do is simply to crosscheck different batches of documents to obtain independent confirmation of their evidence. If that is true, why then would they still need a journal concerned with method?

Actually, this type of reasoning is a complete fallacy. In fact a journal of method is just as much needed today as it was in 1974. For starters, the reasoning of the crosschecking-is-enough crowd ignores the whole documentary context: the institutions that generate written documents; the goals for which they were generated; the conditions under which that happened; the

\footnotetext{
${ }^{1}$ For an overview of what was eventually achieved to redress the situation with regard to written sources, see Beatrix Heintze and Adam Jones, eds., European Sources for SubSaharan Africa before 1900: Use and Abuse (Wiesbaden, 1987) (=Paideuma 33).
} 
multiple links between authors, between institutions, and between the batches, series, and genres of the papers they generated. Moreover, people with such attitudes do not ask any questions about how numbers are generated and manipulated, nor do they care for the primary or secondary character of documents in the naïve belief that all unpublished documents must be primary documents. In fact, the rules of evidence are just as necessary for handling evidence from the recent or even immediate past as they are for evidence from all other periods everywhere. Unfortunately, one does not have to search far to find works about the recent past that illustrate the baneful consequences of disregarding methodology. Their flaws range from the elementary, such as the failure to spot plagiarism and the consequent anachronism, or to identify errors in the totals of sums for instance (quite a common occurrence!), to the more complex, such as a total reliance on summaries of summaries of batches of documents rather than on the primary data themselves, or a lack of awareness of a certain form of feedback, viz., the adoption of prejudices, clichés, or generalizations proposed by previous writers as one's own without any examination of their validity.

While some methodological traps can occur in bodies of evidence, whatever the period or place studied and whatever the overall profile of sources associated with them, others are only frequent, or even exclusive, to the particular profiles of the sources for certain periods or places. Obviously, it should be an urgent priority to identify, explore, and discuss all such particularly relevant issues of method and a journal of method is the ideal forum to do so. The plethora of official written documents that confronts students of the colonial period, for instance, is a good example of such a situation. Scholars often boast or complain about it, without actually realizing that this plethora of documents poses its own particular methodological conundrums. To begin with, the wealth of data in official colonial archives often paradoxically hides gaping lacunae, for instance, in the field of social history. Some of these can be filled by cross-cutting groups of written sources or by the eliciting oral history.

Yet turning to oral history raises a whole new set of questions, from the initial research design (a notion many historians remain seemingly unaware of), including sampling, to interpretations of such testimonies that take into account the interaction of memory and history, and finally to the need to make these testimonies fully accessible to all researchers. Secondly the plethora of documents in major archival repositories also privileges the study of certain well-documented questions intentionally, because that was the goal of those who ordered the generation of such documents. In this way such large bodies of archives cunningly define the terms of their colonial debate and that of course raises its own set of questions. Last, but not least, 
the study of any large body of sources also raises issues of choice and sampling.

The plethora of documents is only one of several special features that stand out in the profile of evidence for the colonial period in tropical Africa, while the post-colonial period has its own distinctive mix of sources. In that period, for instance, official archival materials are usually far less bulky or available, and less prominent than in the previous one, while various other types of sources form a very different profile. Typically, the new mix includes a wide variety of scholarly studies (many based on samples), archival material generated by foreign agencies (many NGOs), reams of audio-visual material and recorded oral data, and local fictional literature and film, as well as a burden of instant history often generated by journalists, but sometimes also by other political commentators. How to cope with this amalgam of sources poses as many particular methodological challenges as other periods do. As a consequence, this period needs a journal of method just as much as any other in order to cope with the new challenges.

\section{II}

It is not possible in a single article to demonstrate fully the continued need for further studies of method in all the various domains that have just been mentioned in passing, but it is useful to develop at least one or two examples of such crucial issues. Let us first turn to the question of the general methodological challenge raised by any use (that is, whatever the disciplines involved) of interdisciplinary evidence, by historians of Africa. An interdisciplinary approach has long been a mantra in this field, and its practice has loomed quite large in the historiography of the continent ever since academic historians turned to African history. ${ }^{2}$ Yet, and despite all this, and despite some spectacular failures of particular schemes in the past, general methodological implications of such research remain quite inadequately explored, even in HA. Let us then focus on an issue that is particularly relevant to recent colonial history: how to apply the overall rule that all the relevant sources must be consulted. Can this be applied to large amounts of either documents or potential oral testimony, or of any other data-and should it? How have historians in the past actually coped with this question? Should they know more about sampling?

${ }^{2}$ It is typical that no separate article has been devoted to the methodology of interdisciplinary research in either of the two recent volumes about sources and methods, Toyin Falola and Christian Jennings, eds., Sources and Methods in African History: Spoken, Written, Unearthed (Rochester 2003), and John E. Philips, ed., Writing African History (Rochester 2005) 
Ever since the publication of the first issue of The Journal of African History, followed by Daniel McCall's Africa in Time Perspective, interdisciplinary research has occupied a central place in the historiography of Africa. ${ }^{3}$ At first it was believed that simple pluridisciplinarity would do: the simple addition of the results concerning a common query about the past discovered by research in different disciplines would yield a coherent body of historical evidence. Consequently, a number of research schemes were set up with that goal in mind. ${ }^{4}$ But soon it became clear that such schemes failed to achieve their goal, in that no historical synthesis emerged from any of them. Rather, the various scholars involved merely studied the evidence pertaining to their own disciplines, without proceeding to amalgamate the results into the elaboration of a common history as had been expected.

Thereupon historians began to think that the solution to this problem was to train individual scholars in whatever disciplines were involved in constructing history in Africa. Starting in the later 1960s a number of graduate students in the United States took this approach to heart. Quite a few of them combined history and social anthropology, one or two history and archaeology, and at least two history and linguistics plus oral literature. But the next cohort of graduate students quietly abandoned this approach, in part because of the career costs involved, in part because of a dislike for the turf battles that soon erupted between disciplinary "insiders " and the new interdisciplinary "outsiders," and in part because the goal seemed too utopian, a feeling Wyatt MacGaffey summed up in his famous observation that"African Historiography became the decathlon of social science."5

By the late 1970s, the whole interdisciplinary enterprise seemed to have come to a dead end, and even the most dedicated scholars (mostly in anthropology and history) lowered their expectations. They now limited their forays into interdisciplinary research to the acquisition of the necessary technical competence in whatever applied bits of an another discipline they needed in order to solve the problem they were studying, for instance, in specialties such as demography, epidemiology, or economics. On the other hand, scholars from other disciplines made incursions into history and wrote historical sketches whenever they deemed it necessary. Quite often such practices led-and still lead-to recriminations between scholars from different disciplines. With reason, professional historians often find fault with the product of scholars from other disciplines while the latter, with equal reason

\footnotetext{
3Daniel McCall, Africa in Time Perspective: a Discussion of Historical Reconstruction from Unwritten Sources (Boston, 1964).

${ }^{4}$ The most famous ones of these were the Benin and Yoruba research schemes.

${ }^{5}$ Wyatt MacGaffey, "African History, Anthropology, and the Rationality of Natives" $H A$ 5(1978), 103.
} 
are often appalled about the incompetence of historians when they use data pertaining to their disciplines.

Nevertheless, the rate of success for more modest endeavors has been high enough to encourage researchers to continue with this approach, especially when fieldwork is involved. Today the most common, satisfying, and successful practice of interdisciplinary research remains the combination by a single scholar of ethnographic fieldwork with a discipline in the social sciences or humanities other than socio-cultural anthropology, such as history, political science, or linguistics. Some research of this sort has achieved spectacular results. Edward Wilmsen's Land Filled with Flies, in which archeology, history, and ethnography are combined to argue against a primordial San way of life is a good example of this. ${ }^{6}$

In addition, and with little fanfare, modest interdisciplinary projects about specific well-defined issues and conducted by small groups of scholars specializing in the required disciplines have also recently become more common again. Such projects include, for instance, one by Carola Lentz, involving history, cultural anthropology, and forestry in Ghana, and another involving history and sociology conducted by the Mouser family. The first one was quite successful, whereas the second one failed, i.e., did not result in a joint synthesis. ${ }^{7}$

Given these different outcomes, one wonders what leads to success in such endeavors and what to failure. Yet, despite the importance of interdisciplinary research in African history, and despite the failure of so many studies, historians have hitherto paid little attention to the methodological problems involved. Thus Barbara Cooper opines that in practice when sources are scarce most historians use the results of one discipline to crosscut those of another. She continues: "[o]ur confidence in our reconstructions of the past derives in part from the ways in which these various sources and methods, when used together, can refine, challenge, inspire, reinforce, or confirm one another."8 They can, but they also cannot, and one should be curious about that. Actually the failure of so many interdisciplinary endeavors by itself already indicates that there must be more to the operation than

${ }^{6}$ Edward N. Wilmsen, Land Filled with Flies: a Political Economy of the Kalahari (Chicago, 1989). This volume has triggered a major polemic and a complete re-evaluation of the use of ethnographic evidence in archeology.

${ }^{7}$ Carola Lentz and Hans Jürgen Sturm, "Of Trees and Earth Shrines: an Interdisciplinary Approach to Settlement Histories in the West African Savanna" HA 28(2001), 139-68; Bruce L. Mouser and Nancy Fox Mouser, “A Rocky Road to Publication” HA 31(2004), 257-61.

${ }^{8}$ Barbara M. Cooper, "Oral Sources and the Challenge of Africa History" in Writing Africa History, 191, with emphasis added. 
just to place independent results (and they are no always really independent!) of one discipline next to the other one.

It is this can/cannot happy-go-lucky stance that explains why far fewer articles about the methodology involved in interdisciplinary research have appeared in History in Africa - or elsewhere-than one would have expected. Yet, from its second issue onwards the journal has published the results of studies based on interdisciplinary research. In the fourth issue (1977) for instance one finds a piece (typical of those times) in which optimistic attention is drawn to the usefulness of geology/meteorology for dating some oral traditions. ${ }^{9}$ More importantly, the same issue also carried a seminal article by the archeologist Pierre de Maret and the linguist François Nsuka that combined linguistics and archeology to discuss the first appearance of metallurgy in Bantu-speaking Africa. That study was seminal in that its findings became the cornerstone of all further research on the issue, and also because its very success demonstrated the potential of this type of interdisciplinary studies. ${ }^{10}$

But if we leave contributions aside that publish results from interdisciplinary work or propose the use of new disciplines for interdisciplinary study, only two pieces in the journal have specifically raised issues related to the interdisciplinary approach itself. The more specific one is the contribution by Bruce (the historian) and Nancy (the sociologist) Mouser. It indicates how the historian's respect for concrete evidence and contingency clashed with the sociologist's validated generalizations and their inclination to explain historical situations by reference to these. A more general article by Ato Quayson is aptly entitled "Means and Meaning: Methodological Issues in Africanist Interdisciplinary Research." 11 It involves literary criticism, socio-cultural anthropology, and history. It starts by asserting that "the theoretical implications of interdisciplinary study and the issues that it generates for questions about different types of knowledge does not seem to have engaged the attention of scholars," and it finds that "there will always be a tension in interdisciplinary analyses between different disciplines because of the differing discursive histories that each discipline brings to bear on the interdisciplinary configuration." 12

${ }^{9}$ Ronald W. Davis, "Volcanic Dust in the Atmosphere and the Interpretation of African Eclipse Traditions" $H A$ 4(1977), 31-41.

10Maret/Nsuka," History of Bantu Metallurgy: Some Linguistic Aspects" HA 4(1977), 43-66.

${ }^{11}$ Ato Quayson, "Means and Meaning" HA 25(1998), 307-18. The disciplines involved here are social anthropology, literary criticism, and history.

${ }^{12}$ Ibid., 307, 318, with emphasis in the original. 
While Quayson's assessment and his findings are of considerable interest, still the theoretical issue raised and some related questions need to be explored much further and discussed much more in the light of many different concrete cases to help all of us to cope with the problems involved. Clearly $H A$ would be the ideal forum to pursue such a discussion. The following remarks are merely an initial contribution to such a debate. Let us start with the obvious: the main problems encountered with interdisciplinary approaches -whatever the disciplines involved-have not lessened over time, and mutual recriminations between scholars from different fields involved in such projects continue as before.

At first glance, such frictions may well seem to be merely turf battles and not worthy of much attention. That is not so. Some confrontations flow from the undeniable fact that full-time insiders have more experience with the data in their discipline than outsiders do. Hence they are more often correct than not on points of interpretations about evidence. Yet in actual fact most confrontations often have little to do with technical competence at that level. They run much deeper. They deal with fundamental differences between the disciplines involved and not just differences with regard to their goals - that, one expects-but also with regard to their practice, that is the whole way they go about their work, and that is less expected, and hence all the more remarkable.

To demonstrate this I choose a single recent case involving linguistics and history. The debate in this case involves a historian and a linguist, and concerns the conclusions to be drawn from the presumed oldest vocabulary in Bantu languages relating to iron/iron smelting. We pick up the debate only after both sides had reached agreement about the evidence used..$^{13}$

The historian concluded that the evidence shows that iron-smelting was not invented in the Bantu-speaking subcontinent, but came from West Africa, because the spatial shape of the distribution of the vocabulary was congruent with that of the distribution of the relevant archeological sites, and because this vocabulary was the oldest one known and hence could only stem from the time of the diffusion itself. The linguist disagreed because in principle linguistic data by themselves cannot offer any proof as to the chronology of a diffusion. Therefore no conclusion can be drawn.

What lay behind those different conclusions? First, there was a difference in goals. Linguistics is the study of language in general and strives for

\footnotetext{
${ }^{13}$ For the data see Jan Vansina, "Linguistic Evidence for the Introduction of Ironworking into Bantu-Speaking Africa" $H A$ 33(2006), 321-61. The professional linguist, Koen Bostoen, and I debated the case by correspondence.
} 
universal truths valid for all languages. When linguists study technical vocabulary, they aim to arrive at conclusions of general value for the field of semantics. In contrast, history is always contingent. Its goal in this case is just to find out whether iron-smelting started in Bantu-speaking Africa (and beyond sub-Saharan Africa), either by independent invention or by diffusion from elsewhere.

Yet the difference in goals is only the beginning. Just as important is a whole list of differences in the procedures used to accumulate and evaluate such data. First, the choice of a topic: either with an eye on universal value (semantics) or as a "substitute" for genuine historical proof (that is, the interpretation of the linguist!). Given the goal of universal validity, the linguist will choose quite a narrow topic- that is, only a few words to be studied at a single time as opposed to the historian, who goes for a broad topic, involving many words-indeed, in some cases, hundreds of words. For linguists, historical conclusions are merely a by-product of fundamental research about semantics; hence they select a few words at a time so as to be able to study them in depth. It does not matter to them if by this procedure it will take about a century or more to reach historical conclusions. Historians obviously disagree, so they study many words to reach conclusions in a very short time span even though their examination often remains quite superficial.

At a deeper level still, there are even more fundamental differences between the two disciplines in the treatment of evidence. Linguists deal in certainties, historians in probabilities; linguists want statements that are absolutely valid, historians are content to have statements that are temporarily valid (i.e., until further notice). It follows that linguists have a rigid standard of proof, because it must be absolute, while that standard is always relative for historians, because further evidence can always overturn it. Consequently, any error in linguistics is more dramatic and damaging to the whole construction than it is in history. In that field most errors are less than earthshaking and indeed often quite fruitful, because history works with probabilities and proof of error rules out one of the likely probabilities. Finally, for linguists there should only be one possible interpretation -one truthwhile historians recognize that the evidence often allows for several equally valid interpretations or truths. All of this is embedded in the disagreement between the conclusions drawn by linguists and historians in the matter of the Bantu vocabulary of iron metallurgy.

Still beyond the linguist's "not proven" or the historian's "proven," there lies a common conclusion that could be phrased in as follows: "until further notice, iron smelting seems to have spread into the subcontinent from West Africa" or more exactly, "[f]or the moment, the most probable explanation 
from the evidence by far is ..." Such a careful conclusion is actually quite helpful in that it settles the current state of our knowledge about a major point in the history of technology, but reminds us at the same time that future research-for instance, in archeology or archeometry-remains necessary and might overturn current understanding

A second major problem with the results of interdisciplinary research is the reverse of the one just addressed: rather than recrimination, we find spurious agreement among scholars from various disciplines. The very same scholars who insist on the greatest rigor in the analysis of data from their own fields often seem to assume that equally high standards are practiced in other disciplines, and hence they can be quite gullible about results obtained in those disciplines. A prime example in African Studies is nearly everyone's eager acceptance based on mitrochondrial (mt) DNA that Eve was African. That conclusion tends to be accepted without question, in large part because it agrees with our own inclinations or prejudices as Africanists. Yet, how many among us can actually show others how this conclusion was reached and why it is convincing? How many historians are brave enough to disagree competently with "Genetics, Egypt, and History" by S.O.Y Keita and A.J. Boyce? 14 Yet there is obviously a lot to discuss there (to begin with, the samples used)!

In general, we should admit that we are easily blinded by sciences with which we are barely or not at all conversant. Even though all scholarship shares fundamental rules of evidence (and logic), we cannot apply such rules to an environment that is so unfamiliar that we do not even understand what the evidence is, how it is obtained, and what it means. We should therefore recognize our ignorance and withhold judgment about such assertions. In general, all we can do in such a situation is to rely on the opinion of other scholars who are thoroughly conversant with the discipline in question. Even so, if we want to use such results for our own research we should at least become familiar enough with the discipline in question to follow the processes by which it reached its conclusions in the case under review, from the finding and gathering of data to the interpretations made of them. It is never advisable to surrender to a blind belief. It can be quite harmful to do so, because unsubstantiated belief tends to hide what we don't know and hence to misdirect further research.

This all too concise probe into the theoretical difficulties raised by the pursuit of a single instance of interdisciplinary research tells us that, contrary to widespread belief, this kind of research cannot be expected to yield results that only need to be added one to the other to yield the sum of the

${ }^{14}$ S.O.Y. Keita and A.J. Boyce, “Genetics, Egypt and History" HA 32(2005), 221-46. 
evidence sought. The differences in the goals and the practices of the various disciplines explain the high rate of failure common to such ventures. The case of the Mousers is almost paradigmatic here. Yet this hurdle can often be overcome by analyzing the various findings and disagreements in far greater depth than is usual. The scholars involved can then often express their precise conclusions about a single issue in a common way, usable by all, and thereby advance knowledge. Conversely, they should never just accept what they don't understand because that does impede further advance of knowledge. Considering that all the above merely flows from the findings of a single case, it is obvious that many more different casesinvolving different pairs and numbers of disciplines for instance-should be studied before historians can feel fully confident in the methodology to be applied to interdisciplinary research. Hence, one can forecast many more articles for future issues of a journal of method.

\section{IV}

It is a general rule that once historians have chosen the concrete issue they want to study, they need to consult all the sources that are relevant to that issue. Problems arise when they face a plethora of relevant sources, e,g., when vast amounts of written documents need to be read, or huge numbers of relevant oral testimony gathered. What then is the researcher to do? In such circumstances, the other social sciences usually rely on general random samples or on random samples stratified according to criteria relevant to the research. Yet it is rather striking that most historians of Africa have not embraced this approach, but have tended to rely on other solutions. These have been (a) to consult a portion of the whole and claim that the results hold for that portion only, in the expectation that other scholars will study further portions of the record; (b) to set up a huge research scheme and work through all the relevant data; (c) to consult a small portion of relevant sources and simply extrapolate the results to the whole without further comment. The first two of these approaches are valid enough. The first solution is the one most favored by historians in general, both in theory and in practice. Ideally, scholars first generate monographs (often doctoral dissertations), and once a set of these has been produced, they are followed by a general synthesis of all their results. In practice, however, this ideal of inductive logic often works rather differently. It all starts with the publication of a sweeping hypothetical overview based on the limited research results available. This gives the necessary impetus to test it by the production of a series of monographs, until a new synthesis emerges and a consensus is reached, often only a generation or so later. The study of twentieth- 
century century Africa by historians, however, is still too recent to have developed far beyond either the initial provisional hypotheses or a few detailed monographic studies.

The second approach has been rather rare, because it requires the acquisition of significant financial and human resources as well as the fashioning of an appropriate detailed research design. Africanist historians are not used to setting up large projects and detailed research designs. Indeed, they have, as far as I know, never even discussed the subject of research designs at all. In my own experience, though, I have been able to set up well-supported projects in oral history twice: first in Rwanda, and later on an even larger scale in Libya. The goal of the second study was to gather full oral testimony of all the still surviving Libyan veterans about the long colonial conquest of the country by Italy (1911-1933). The research design required was quite complex. In a first stage it encompassed ways to find all the surviving veterans in the country, the training of a dozen or so young researchers in the detailed available history of this conquest and, more importantly, in the theoretical and practical aspects of oral interviews and the development of precise protocols for interviewing and recording. A second stage saw the deployment of the trained researchers to do fieldwork across the whole country in a systematic way, so as not to omit any village or camp. Parallel to this, and in a third stage, came the setting up of a laboratory to handle tapes, as well as the gathering, transcription, and, if necessary, translation into Arabic of the tape recordings, and then their indexing and the organization of their archival repository. ${ }^{15}$

The Rwandan project was less ambitious. It focused on gathering all the historical tales from the repertoire of all surviving storytellers. ${ }^{16}$ The steps and the issues were quite similar to the Libyan project, however, except that in this case a small-scale initial pilot scheme had to be set up to acquire the information needed to create the full-scale research design .

It is noteworthy that as far as I know no articles at all have been written by historians of Africa about such essential topics as research design, practical training for interviewing, the use of protocols, standardized indexing of tape contents, and rather little about archiving oral materials. Perhaps this is

\footnotetext{
${ }^{15}$ Over the years the Libyan Studies Center in Tripoli has published dozens of volumes of these testimonies. The only result in English about the whole project is a summary of findings about memory and personal reminiscences; see Jan Vansina, "Memory and Oral Tradition" in Joseph C. Miller, ed., The African Past Speaks: Essays on Oral Tradition and History (Folkestone, 1980), 263-77.

${ }^{16}$ Jan Vansina "Historical Tales (Ibitéekerezo) and the History of Rwanda" HA 27(2000), 375-414, for these sources. Transcripts on microfilm are at the Center for Research Libraries and a few other Africanist libraries.
} 
a consequence of the rarity of such projects, but one doubts it. After all, research design-whether conscious or unconscious-is a feature of all historical research, while the other points mentioned relate to oral history, whatever its scale, and should be widely discussed. Among the other topics mentioned, interviews are the most crucial. Yet historians of Africa mention them so rarely that the subject is barely worth two pages in a recent survey of sources and methods in African history and even that is mostly copied from a general social science text. ${ }^{17}$ To every historian who has worked extensively with interviews, the confident typology of that text-dividing interviews in four groups as structured, semi-structured, unstructured, and the group interview-caricatures reality and only underscores how little methodological or practical attention has been paid to the subject in the relevant literature.

When there are masses of written material, as in the case of colonial administrative archives, one can also often find regular (usually annual) summaries of whole batches of them. In Belgian colonial practice, the local administrator of a territory wrote such a summary once a year and forwarded it to the district commissioner, who then summarized the summary, bundled it with similar documents for the other territories in his constituency, and forwarded it to the provincial governor, who sent it on to the government general. The last summary of the whole lot of summaries for the whole colony was then fused into a last annual report that was sent to the Belgian Parliament and published. Some scholars have been content to rely only on that last summary as representing the essence distilled from all those masses of paper and have based their histories on it.

The least one can say about this procedure is that it is far too superficial, and that in accepting such "distilled evidence" the historian accepts the official judgment of all the officials at the various levels involved as to what happened and what it signified. Therefore, the practice actually shortcuts the possibility of any really original research, and prevents the scholar who uses it from reaching her or his own insights into the very substance of their study..$^{18}$ Actually, rather than to rely on such summaries of summaries it is perhaps more defensible to sample the vast underlying body of documents systematically, even if wholly arbitrary criteria are used-for instance, that only documents of every seventh calendar year in the corpus will be consulted. Indeed such an approach, combined with the study of the annual

${ }^{17} \mathrm{On}$ interviewing, the passage in Isaac O. Albert, "Data Collection and Interpretation in the Social History of Africa," in Writing African History, 299-300, barely scratches the surface.

${ }^{18}$ Such parliamentary reports are the main source used in Joseph Gahama, Le Burundi sous l'administration belge (Paris, 1983) 
summaries to check the relative representative character of the years chosen, seems safe enough.

The third approach consists in extrapolating general conclusions from the results of the study of an arbitrary small portion of the available sources. Whether this is ever acceptable depends strictly on the goal of the research. If the goal happens merely to document the general tenor, chronology, and spatial spread of a sensational public rumor, it makes little sense to interview every single person in a community where the rumor spread nor is it necessary to go through vast amounts of written documents about the rumor, beyond the point at which one has obtained testimonies and documents that establish the chronology and the geographic spread of the rumor. ${ }^{19}$ To try and get all the possible testimony would be a huge waste of effort. Such cases, however, are the exception. The following situation is far more common to pursue our example. When variations in the content of a rumor matter-for instance, of different mentalities within an area or a community - one must either gather all the data, or obtain all the significant variants by some other means. The only other valid way to do this would be by sampling.

Usually one's research goal requires the perusal of all the relevant documents or oral data, and it remains completely unacceptable to consult some data and abandon the rest haphazardly, even if one claims, as some researchers do, that the results of one's selection are "paradigmatic "or "representative" of the whole. Unfortunately, this approach is the very common. In particular, the practice of generalizing from a few people encountered more or less by chance to a whole collectivity is completely invalid, however common it may be in research, especially about oral history. The equivalent of this practice among historians using written data would be to stumble on a few documents, use them, and then abandon all the others. Obviously, such practices are completely unacceptable, whatever the volume and the nature of the data to be consulted.

A particularly insidious tendency to generalize from a small fraction of data is the use of a single autobiography, whether solicited or not, to extrapolate from the result to a whole community. ${ }^{20}$ Apart from crucial questions

${ }^{19}$ See e.g., the input into Luise White, Speaking with Vampires: Rumor and History in Colonial Africa (Berkeley, 2002). Are her sources sufficiently representative for space and time to allow for the correlations and conclusions she draws?

${ }^{20}$ For example, Marjorie Shostak, Nisa! The Life and Work of a !Kung woman (New York, 1983). This biography was solicited and constructed out of fifteen interviews. It is therefore as much the work of Ms. Shostak as of Nisa! The reader is given ethnographic information to understand the story, but at the same time people are urged to read the biography to enter in the realm of Bushman life. As a result, proper use of such data in any historical work can become very tricky. 
of authorship and audience that are raised in all cases of solicitation, the main issue in such cases remains that what happened to the protagonist of the biography, however valuable in itself, is valid only for that person. It cannot be extrapolated in any way as the normal usage in a whole community, unless this is clear from the biographical evidence itself. To describe norms, one must rely on other sources as well, be it by drawing on already known data or by supplementary research aimed at establishing precisely how paradigmatic documents like the biography really were. At best, the narrator herself or himself makes clear what events or situations were common or expected in his or her community, and which ones were exceptional and individual.

Samples are routine in the research kit of the other social scientists, but they are quite rare in qualitative historiography and many historians know or understand little about the process of sampling. In fact the subject is practically absent in $H A$, at least as distinct from the use of statistics. ${ }^{21} \mathrm{I}$ am aware of only one article about sampling specifically written for historians of Africa, especially for those who work in the colonial and post-colonial periods. ${ }^{22}$ The main point that Dennis Cordell makes is that the raw data from interviews and questionnaires used in gathering demographic and other social samples are often rich sources for the historian. The use of social science samples has been growing during the colonial period, while during the more recent post-colonial era, they have become essential sources for any historian. But in order to exploit them, historians must be informed of how they were generated, how representative they are of the wider populations, and how to find them. To do so they also have to become conversant with the methodology of samples.

To lay out that methodology in sufficient detail requires a small monograph, not a paper. Hence I can only mention a few essential points here. Sampling consists in taking a fraction of a dataset that is representative for the whole set so that one can safely extrapolate the results from that fraction to the whole set. It presupposes that the whole set (or "universe") sampled is homogeneous with regard to the issue studied, and that its constituent units are sufficiently equivalent, so that one can stand in one for another. For example, in a given, mostly inbreeding, population, people's bodies are sufficiently similar that one can assume that a fraction of the population will exhibit the same internal distribution of variation in one element as will

\footnotetext{
${ }^{21}$ Raymond A Gervais and Richard Marcoux, "Saving Francophone's Africa Statistical Past" HA 20(1993), 385-90

22Dennis D. Cordell, "Sample Surveys: Underexploited Sources for African Social History," in Sources and Methods in African History, 376-92. It is typical that sampling was not deemed worth a chapter in the contemporary Writing African History.
} 
occur in the whole population (or "universe"). Thus the distribution of blood groups or of DNA can be studied by sampling. Note, however, that the whole population must be arbitrarily defined (e.g., all Egyptians) before a sample is taken, and therefore that there must be reason to suspect that it is homogeneous, as defined. If it is not, the sample will not be valid and its heterogeneity usually shows up in the results, but not in all cases, so one cannot assume that the results validate the definition of the universe.

Note also that the topic of the research (e.g., blood groups of the ABO system) must also be defined with precision. It is therefore obvious that no sample can be set up if one does not have prior information about the universe to be studied, and about the topic to be studied. Such information is usually obtained by means of thorough initial pilot projects .

Secondly, because history, in contrast to the social sciences proper, is always contingent, a historical situation where individual experiences are fully interchangeable does not exist-even in the life of identical twins. Hence, samples can deal only with features common to groups-for instance, in a defined group some men are married and have children, some are married but childless, and some are bachelors. That allows sampling to be set up with regard to the numbers and durations of marriages in general within this group. But the sample will not be valid as a substitute for the detailed history of any given marriage in the set.

There are various technical ways to construct a valid sample. Most samples of a homogeneous universe are random and involve the fewest possible number of units to be statistically (that is, mathematically) valid. These situations are not all that frequent in historical research. Historical samples are often stratified. When a universe is not homogeneous, but consists of mixed sets of subgroups, each of which is internally homogeneous with regard to the feature studied, one can sample the subgroups across the whole universe. Thus in a given country one can sample urban and rural subsets and even combine a random sample of rural villages with non-random urban samples from the dozen biggest towns in the country. For, besides random samples, there are also various kinds of systematic samples. Actually the variety of possible valid samples is huge. Hence, one of the reasons numerous contributions about sampling in history are necessary is to present and learn from the whole spectrum of sampling that has been used by historians. But we cannot survey even a few of these so I limit myself to a single example: how to build a valid sample to obtain the narrative oral traditions current in Burundi.

A study of historical narratives in Burundi needed to uncover not just a specimen of all the different narratives, but the full range of all variants of every known such tale. As there were hundreds of thousands of potential 
tellers, a sample had to be set up. ${ }^{23}$ First, a single pilot study was carried out during nearly four months in a sub-chiefdom where the tombs of the Rundi kings were located, and where the two most influential Rundi chiefs also happened to reside. From this emerged the main criteria for both the number and the variability of the traditions to be studied. These criteria were then checked with a second pilot study in a district where the tombs of the queen mothers were located, but where no major chief resided.

When the sample was set up, it supposed that the number and the variability of oral histories varied (a) with spatial distance; (b) with the presence or not of historical sites such as royal tombs, former capitals, and ritual sites; and (c) inversely with nearly impassable major mountain ranges that reduced the transfer of information between regions to a trickle. The unit of collection was to be the sub-chiefdom. In each of these, every reputedly knowledge able adult man was identified first by a helper before narratives were recorded or noted by hand. Almost all women refused to be interviewed, because in Rundi culture they were not supposed to know this information, even though they obviously did. A small questionnaire was developed for each of the male narrators, including their social identities (=these then did not include Hutu/Tutsi/Twa!), the oral genres known, and their knowledge of all historical sites. The sample itself was not completely random since all the major historical sites were included as points to be sampled. The distance between collecting points was arbitrarily set at 30 kilometers (just under 19 miles). These points (that is sub-chiefdoms in which the points fell) were found by drawing 19-mile-diameter circles around the known points, and then by random choices among the sub-chiefdoms outside those circles.

Then the research in the sample was carried out. During its execution two regions on the outer limits of Burundi had to be dropped for lack of data. They were both beyond major mountain ranges and the incomplete data gathered there showed that they belonged to a very different narrative universe-as did the narratives gathered in a third and last region, also beyond major mountains. The sample was augmented by some narratives gathered at various times before this research was set up, and the whole was then used as the basis for a monograph. Much later, when more intensive research was carried out by other researchers all over the country, it turned out that the sample had indeed caught all but one of the known narratives of this type in the country and had also caught the major variations of those single narratives. In others words the sample had been an almost complete success. ${ }^{24}$

${ }^{23} J a n$ Vansina, La légende du passé: traditions orales du Burundi (Tervuren, 1972), 1218 , and map 2.

${ }^{24}$ Leonidas Ndoricimpa and Claude Guillet, L'arbre mémoire: traditions orales $d u$ Burundi (Paris, 1984). The authors had access to copies of the results of the sample study. 
The two issues briefly discussed in this paper show that questions of method, including epistemology and historiography, remain just as essential now as they were in the 1970s, both for scholars working on older periods who are usually well aware of this need-thanks to $H A$, among others-and for those working on the recent or even the immediate past who usually seem not as well aware of that need. Besides points briefly mentioned in the text, there are also are many relevant and hitherto practically unexplored issues. We cannot be content to stay with a general handbook about method, we need a journal of method. We need such a forum because we require a record of multiple experiences and dialogue between scholars about such issues. We need it to advance our theoretical understanding of them; we need it to preserve sound standards of scholarship; and we want such experiences recorded in a journal as a practical aid for researchers facing similar issues. In the past $H A$ as provided all this. May it (or a cloned daughter of it) continue to do so in the future. 